\title{
CFD INVESTIGATION OF TEXTILE DRYING TEMPERATURE AND DENSITY IN A INDUSTRIAL STENTER FRAME SECTION
}

\author{
Mesud Ramic, Ejub Dzaferovic \& Amra Hasecic
}
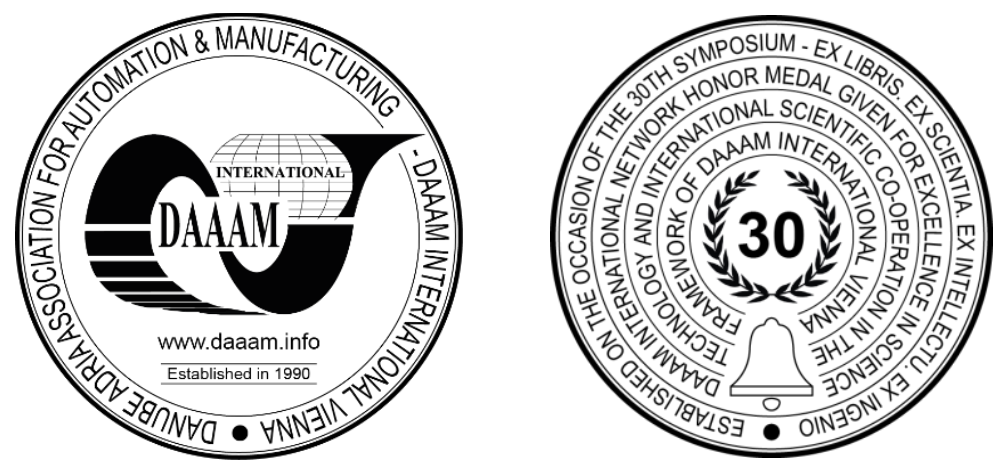

This Publication has to be referred as: Ramic, M[esud]; Dzaferovic, E[jub] \& Hasecic, A[mra] (2021). CFD Investigation of Textile Drying Temperature and Density in a Industrial Stenter Frame Section, Proceedings of the 32nd DAAAM International Symposium, pp.0648-0651, B. Katalinic (Ed.), Published by DAAAM International, ISBN 9783-902734-33-4, ISSN 1726-9679, Vienna, Austria DOI: $10.2507 / 32$ nd.daaam.proceedings.091

\begin{abstract}
Drying as a basic scientific phenomenon has been intensively investigated but limited for specific and real running stenter. Authors approach was to apply scientific methods to investigate real machine performance. This work investigates phenomenon of textile drying under specific technological conditions. Temperature inside the machine chamber has been scientifically proven as a parameter that significantly correlates to energy consumption. Research on such large systems and machines is too expensive and the investigation must involve the digitalization of process by modern computational methods. Previous experimental investigation and 2D numerical simulation of the machine have been used as base for extended investigation with 3D numerical model and appropriate simulation. Goal is to understand temperature and density distribution inside the textile dried in a stenter chamber with simulation under real value parameters.
\end{abstract}

Keywords: temperature; stenter; CFD; drying; energy efficiency;

\section{Introduction}

The first energy efficiency project in Bosnia-Hercegovina (2011) with appropriate measures reflected to $43 \%$ reduced energy consumption [1]. Industrial drying and finishing of textiles is a part of the finishing processes which are energy-intensive processes and interesting from the aspects of energy consumption. Measures for energy efficiency are the focus on energy management, recovery, alternative energy, alternative processes and more [2]. This The basic principles of thermodynamic dependences in drying process of polyester textile materials can be found in the papers where the dependences of drying costs in relation to the humidity parameter [2], nozzle temperature, chamber climate [3] and material stabilization time were investigated [4]. According to the research [6] 39.7\% of energy belongs to heating the air while $41 \%$ is used in the evaporation process of energy breakdown $6.2 \mathrm{GJ} /$ tonne material for typical stenter. Reducing the supply of fresh air to the combustion chamber from 10 to 5 kilograms of air per $\mathrm{kg}$ material, energy savings of $57 \%$ are obtained. Further studies were related to the development of mathematical models [5], numerical simulations and appropriate analysis [6]. The authors investigate the effects of turbulent flows [7], flow velocities on convective heat transfer at individual droplets [8] and turbulent channel flow [9]. 
Base for this investigation are presented in studies with experimental part and defined indicators to understand stenter energy consumption [11], statistical correlation analysis to define relations between parameters [12], 2D and 3D model to understand turbulent flow, temperature and density distribution in area between nozzles and textile [13]. Intelligent manufacturing is one of the key roles in the Industry 4.0 [14], therefor this CFD numerical investigation has been made as further work to understand new aspects of the physical modelling of the process regarding temperature and density distribution inside the textile that is subject of drying. Mathematical modelling in this research include model of heat transfer, model of turbulent mixture flow and mass transport, material characteristics model and boundary conditions [6].

\section{Numerical method and results}

In this study standard Ansys Fluent Academy Package R20 was used for numerical simulation. The investigation model is based on Finite Volume Methodology and numerical solution of equations is based on methods of discretization. Discretization is the process of converting integral-differential equations into algebraic equations [15]. In numerical simulation were used mixture model of the fluid that simulates the phases of water and evaporation, model of solid used for material characteristics. Textile inside the section was approximated as porous media with its porosity characteristics calculated based on [9]. The mixture flow was simulated using RANS approach for the three-phase flow. It solves the transport equation, pressure and velocity by SIMPLE algorithm. A realizable high-Re number k- $\varepsilon$ model was used for prediction of turbulence. The standard wall treatment was applied for providing the wall boundary conditions. Pressure-based solver was used and the results are visualized with different settings such as contours and field vector. Real geometric shape of section, numerical model and boundary conditions are presented at Figure 1. At Figure 2. are showed air temperature and phase density inside the textile for time periods; $t_{1}=0.25 \mathrm{~s}, \mathrm{t}_{2}=0.5 \mathrm{~s}, \mathrm{t}_{3}=0.75 \mathrm{~s}$, $t_{4}=1 \mathrm{~s}$. Temperature inside the textile for time periods $t_{1}=0.25 \mathrm{~s}, \mathrm{t}_{2}=0.5 \mathrm{~s}, \mathrm{t}_{3}=0.75 \mathrm{~s}, \mathrm{t}_{4}=1 \mathrm{~s}$ in $3 \mathrm{D}$ are presented at Figure 3 . The geometric insensitivity test was performed by iterative network fragmentation according [13].

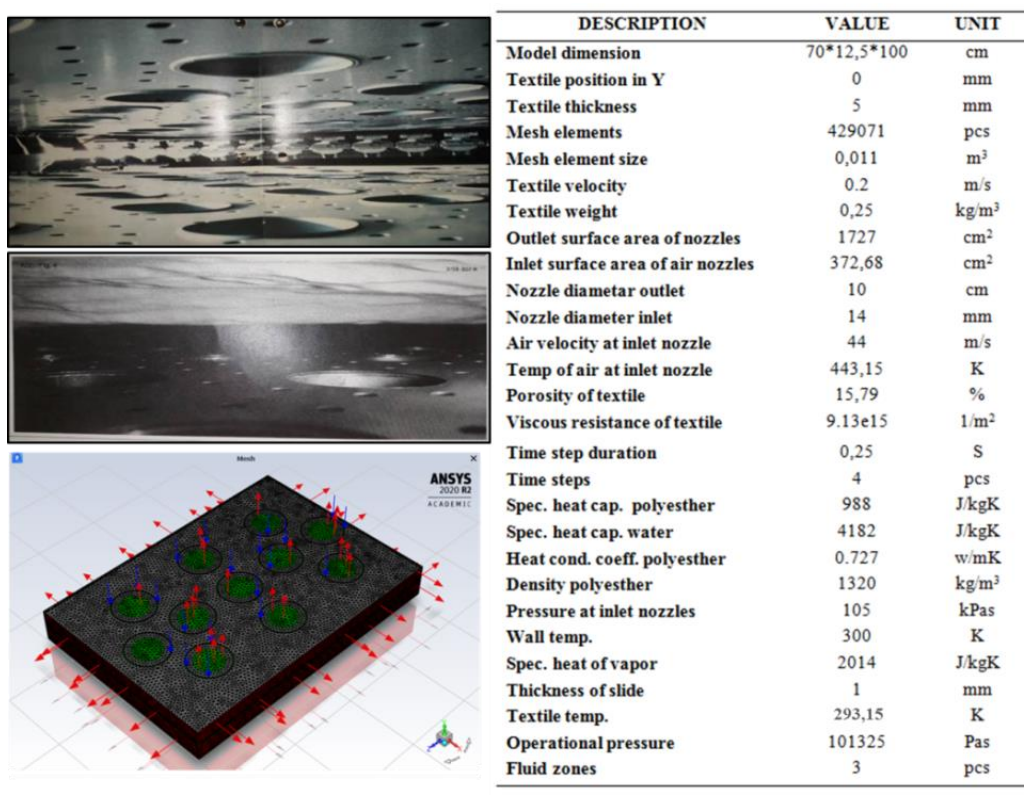

Fig. 1. Real section geometry (left top), 3D numerical model (left bottom) and calculation parameters (right) used for numerical simulation
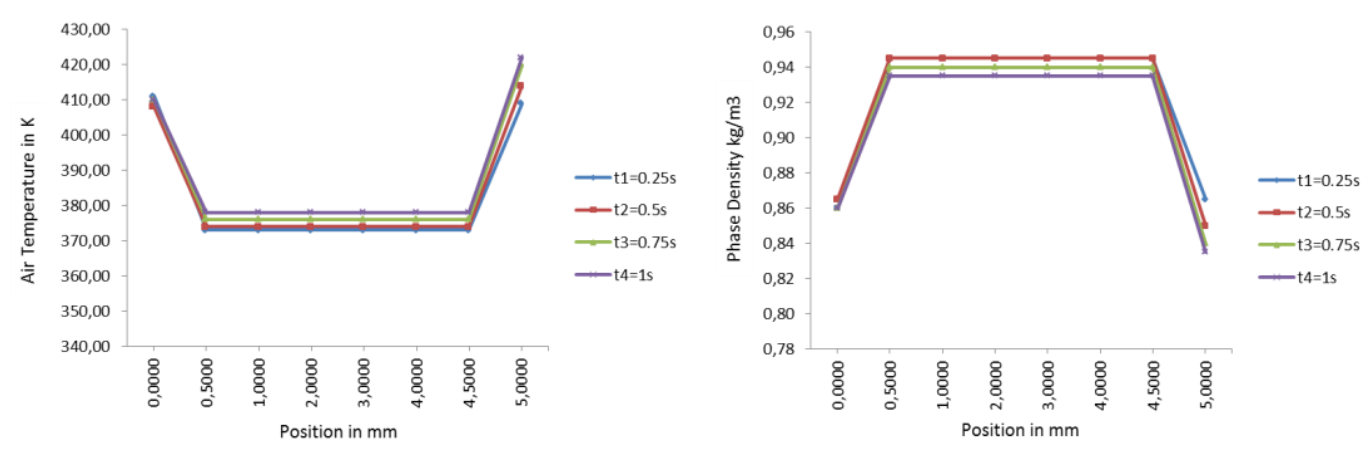

Fig. 2. Air temp. (left) and phase density (right) inside the textile for time periods; $t=0.25 \mathrm{~s}, \mathrm{t} 2=0.5 \mathrm{~s}, \mathrm{t} 3=0.75 \mathrm{~s}, \mathrm{t} 4=1 \mathrm{~s}$ 


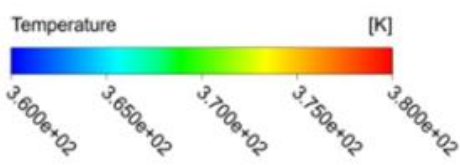

ANSYS

$2020 \mathrm{R2}$
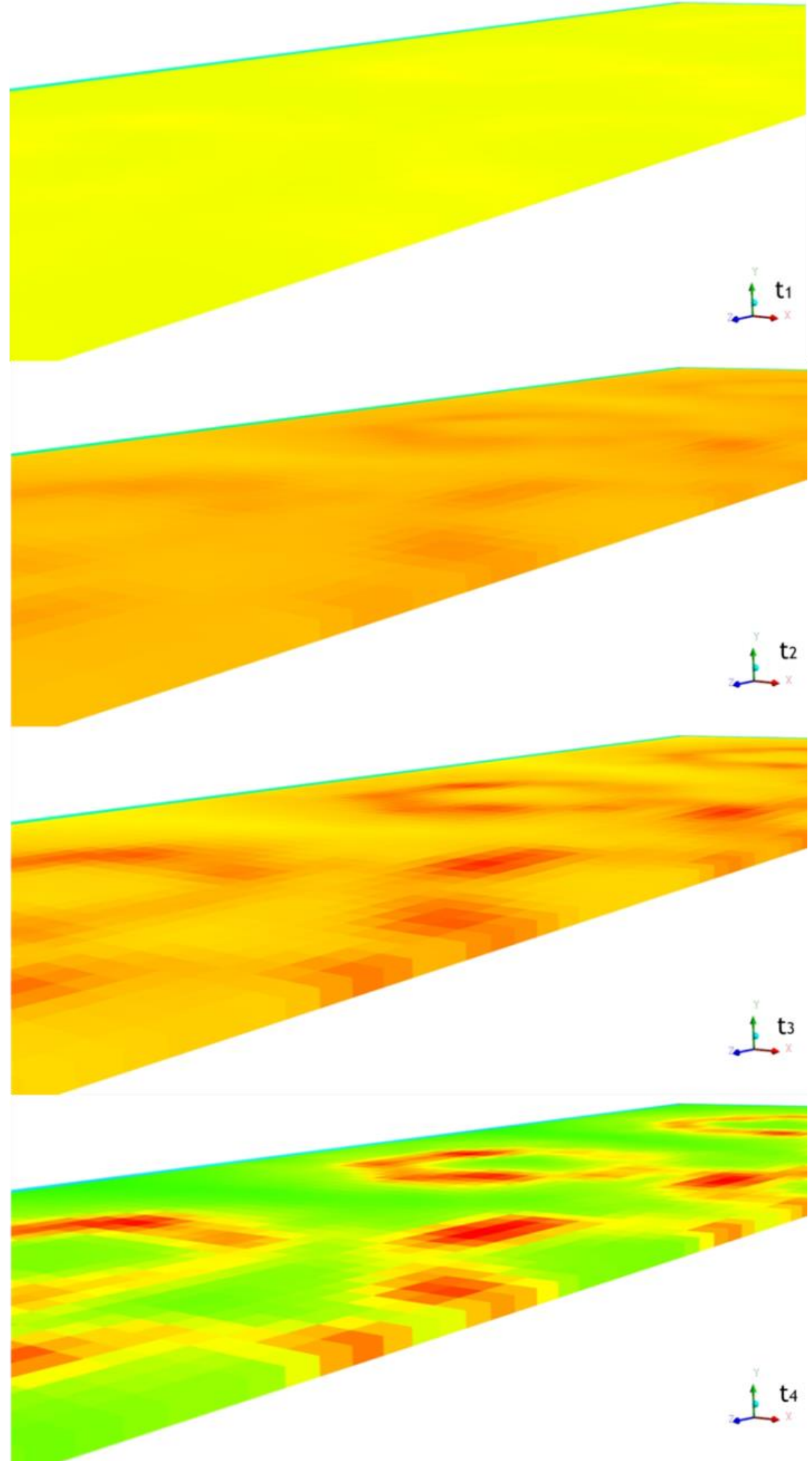

Fig. 3. 3D temperature distribution inside the textile for time periods; $\mathrm{t}_{1}=0.25 \mathrm{~s}, \mathrm{t}_{2}=0.5 \mathrm{~s}, \mathrm{t}_{3}=0.75 \mathrm{~s}, \mathrm{t}_{4}=1 \mathrm{~s}$ 


\section{Conclusion}

The motivation for this research was unknown temperature and density distribution inside the textile in a stenter frame section. The solution for this was to numerically simulate the drying process and analyse temperature and density distribution inside the textile. The temperature and density were calculated and presented graphically. Textile temperature decreases linearly from outside, from both sides to the central line of material. In case of density the process is inversely proportional and the calculated values increase linearly to the central segment of material. From the view of the textile middle section to surfaces, during evaporation process density is decreasing and temperature is increasing. These method and results help us to understand running phenomena in textile and chamber section and could be used as base for simulation with real material characteristic. Limitation in this research represents the model of textile, where phenomena of porous media was used and not the real textile structure with his porosity. Future plans are to investigate the same drying process and phenomena under conditions where textile is modelled as real as possible with yarn characteristics and weaving structure. This will lead to recognition of real interdependence between temperature and density for the appropriate parameters of stenter exploitation. The contributions of this and planed investigation are multiple and this research work is useful from both scientific and professional aspects. The research methodology is traceable and integrative because it includes research in real conditions, calculations and statistical analysis in combination with numerical process simulations, and as such, in addition to its scientific validity, it also has its market applicability. The collected results represent one base for the profession, plant design organizations, designers and textile materials technologists. The database is also useful for efforts to reduce energy consumption its harmful impact on the environment. The results of this study can improve the drying concepts in the textile industry, as well as in all other applications with porous material, and bring closer knowledge about potential savings.

\section{Acknowledgments}

This research did not receive any specific grant from funding agencies in the public, commercial, or not-for-profit Sectors.

\section{References}

[1] Zečević, N.; Husika, A.; Džaferović, E. (2018). Impact of Energy Efficiency Measures on Indoor Air Quality in Building of Mechanical Engineering Faculty Sarajevo, Proceedings of the 28th International DAAAM Symposium, ISBN 978-3-902734-11-2

[2] Al Musa, F.; Qahtani, H.; Owaidh, M.; Qahtani, S.; Noureldin M. (2011). GHG Emissions Reduction Via Energy Efficiency Optimization, ISBN: 978-953-51-4328-4,

[3] Hasanbeigi, A. (2010). Energy-Efficiency Improvement Opportunities for the Textile Industry, National Laboratory, Berkeley

[4] Pabst, M. (1979). Trocken und thermofixieren von Poliesterartikeln unter wirtschaftlichen Gesichtspunkten, Lenzinger Berichte, Vol 47

[5] Wang, Sh. (2020). Process analysis and optimization of open-width fabric continuous drying based on numerical simulation, Textile Research Journal 1-25

[6] Wang, Sh. (2019). A numerical model of the open-width coupling drying process for cotton fabrics based on the theory of heat and mass transfer in porous media, Textile Research Journal Vol. 90

[7] Schmidt, M. (2009). CFD Untersuchung des Auftrags hochviskoser polymerer Systeme in Textilen Verarbeitungsprozessen, Dissertation, Universitaet Duisburg

[8] Guo, N.; Finnerman O.; Strom H. (2016). The effect of turbulent velocity fluctuations on the convective heat transfer to droplets subjected to evaporation and thermolysis, AIP Publishing

[9] Wei, Y.; Hua, J.; Ding, X. (2017). A mathematical model for simulating heat and moisture transfer within porous cotton fabric drying inside the domestic air-vented drum dryer, Text Inst Proc,

[10] Fontana, E.; Donca, R.; Mancusi E.; Augusto, A.; Guelli, S. (2016). Mathematical modeling and numerical simulation of heat and moisture transfer in a porous textile medium", The Journal of the Textile Institute, Volume 107 No 5, 672-682

[11] Ramić, M.; Zrno, A.; Husika A. (2016). Energy flow analysis of stenter Artos Babcock by textile producer Prevent Fabrics, World Textile Conference AUTEX, Ljubljana SLO

[12] Ramić, M.; Hasečić, A.; Džaferović, E. (2016). Dependence analysis of parameters from thermo-fixing process based on IBM SPSS Statistical tool, IEEE Conference, Zlatibor, SRB,

[13] Ramić, M.; Hasečić, A.; Džaferović, E. (2021). Numerical analysis of drying proces in stenter frame section, ICNAAM Conference of Numerical Analysis and Applied Mathematics, Accepted paper, Greece

[14] Kržalić, A.; Hodžić L. (2019). Sustainable engineering challenges towards Industry 4.0, Acomprehensive review, Sustainable Engineering and Innovation, ISSN 2712-0562Vol.1, No.1, pp.1-23

[15] https://ansyshelp.ansys.com, ANSYS Fluent Users Guide, 2021 